Multicultural Parenting: Preparation for Bias Ethnic-Racial

Socialisation in British South Asian and White Families in the UK

Published in 'International Journal of Intercultural Relations'

Humera Iqbal (UCL Institute of Education)

Corresponding author:

Dr Humera Iqbal

Thomas Coram Research Unit

Department of Social Science

UCL, Institute of Education

27/28 Woburn Square

London WCIH 0AA

Email: h.iqbal1@ucl.ac.uk 


\title{
Multicultural Parenting: Preparation for Bias Ethnic-Racial Socialisation in British South Asian and White Families in the UK
}

\begin{abstract}
Ethnic-racial socialization describes how parents transmit information, perspectives and values relating to race and ethnicity to their children in highly multicultural societies such as the United Kingdom. It serves as an important parenting tool to cope with increased diversity. Preparation for bias represents one type of Ethnic-Racial Socialization, in which parents aim to make children aware of discrimination and how to deal with it. Current research in the UK has neglected this area, particularly for second generation families, members of the host society and younger children.
\end{abstract}

This paper discusses qualitative findings from an in-depth cross-cultural study focusing on 90 British non-immigrant White, Indian and Pakistani families with children between 5-7 years old. The study aimed to understand mothers' use of preparation for bias strategies in anticipation of their children experiencing discrimination or following racist incidents in highly multicultural environments using semi-structured interviews. Mothers and children from all groups were found to have experienced discrimination. Preparation for bias served as an important tool used frequently by parents with both proactive and reactive strategies used. It was reported most in the British Pakistani families and least in the British Indian families, with White families reporting intermediary use. Setting was particularly important in White families who discussed 'informal segregation' where they lived causing their transformation to minority members and their subsequent use of preparation socialisation.

The study increases understanding of ethnic-racial socialization and will inform policy and theory on family life in relation to intercultural relations between both ethnic minority and majority groups.

Keywords: ethnic-racial socialization, preparation for bias, proactive socialization, reactive socialization, multiculturalism

\section{Introduction}

In highly multicultural societies, people from different backgrounds are thrown together and interact on a daily basis. The dynamics of this interaction will depend on a number of factors, one of which is the way individuals are socialised to engage with those different from themselves. This interaction is not always positive and can lead to discrimination and prejudice in intergroup relations. The model of ethnic-racial socialisation (ERS) is helpful in understanding how socialisation occurs at the level of the child. It describes the ways parents transmit information, perspectives and values relating to race and ethnicity to their children in diverse societies (Neblett et al., 2012; Hughes et al., 2008; 2006). Preparation for bias represents one type of ERS, in which parents aim to make children aware of discrimination and how to deal with it. In parts of the United Kingdom with extreme 'super-diversity', (Vertovec, 2007) parents are often forced to make such parenting decisions as issues around integration; inter-ethnic dialogue and ethnic identity arise on a daily basis. 
This paper will explore preparation for bias socialisation within the UK amongst British-born Indian, Pakistani and non-immigrant White families with children aged 5-7 years old. Studies have shown that this type of socialisation is used more frequently by minority ethnic groups, yet few studies have explored its use by majority ethnic groups and fewer still have looked at this form of socialisation in a British context. Also, studies tend to examine these processes in adolescents and ignore younger children. This paper argues that increased diversity in the UK has caused host society members as well as certain minority ethnic group members to adapt parenting strategies according to their surrounds, and resulted in some ethnic groups feeling more adjusted while others are being forced to make challenging parenting decisions. Current literature on preparation for bias and new empirical research from a study of family life in multicultural Britain will be used to argue this claim.

\section{Preparation for Bias as a form of Ethnic-Racial Socialisation}

Ethnic-racial socialisation (ERS) is a concept which describes the way in which caregivers transmit information, perspectives and values relating to race and ethnicity to their children. Implicit and explicit messages about the meaning and significance of race and ethnicity, the meaning of belonging to a particular ethnic or racial group and ways of managing discrimination are all aspects of ERS (Neblett et al., 2012; Coard \& Sellers, 2005). A large part of the literature has been developed in the US particularly in relation to African American, Latino and Chinese families (Boykin \& Toms, 1985; Peters, 1985; Spencer \& Markstrom-Adams, 1990; Tatum, 1987; Thornton et al., 1990; Knight, Bernal, Cota et al., 1993; Knight et al., 1993; Ou \& McAdoo, 1993; Quintana \& Vera, 1999). These studies have revealed the highly multifaceted nature of ERS and the importance of it being understood with relation to its content, mode of transmission and the underlying beliefs and aims behind it.

Different forms of socialisation exist including cultural socialisation, preparation for bias, promotion of mistrust and egalitarianism. Depending on circumstances and particular environmental factors, parents utilise particular forms. These forms are by no means mutually exclusive; they can exist within the same instance of socialisation (Hughes et al., 2006; 2008).

In cultural socialisation, parents teach children about their racial heritage and history. Such socialisation encourages understanding of traditions and cultural customs and children's pride in ethnicity or race (Hughes et al., 2006, 2006b; Boykin \& Toms, 1985; Hughes \& Chen, 1999; Thornton et al., 1990; Umana-Taylor \& Fine, 2004). Egalitarianism occurs when parents teach children the significance of individual qualities as opposed to membership in a racial or ethnic group (Iqbal, in press; Hamm, 2001; Boykin \& Toms, 1985; Phiney \& Chavira, 1995 Hughes \& Chen, 1999). Promotion of mistrust involves parenting practices that encourage distrust and carefulness in interracial communication (Hughes et al., 2006; Hughes \& Chen, 1999). Lastly, preparation for bias is a socialisation type which forms the core of this paper and will be discussed further below. 


\subsection{Preparation for Bias}

Preparation for bias relates to parenting practices that aim to make children aware of discrimination and teach them how to deal with it (Hughes et al., 2006a; Hughes and Chen, 1999). This ERS form has been examined with particular reference to the African American group, and can be linked to their history of marginalisation. Hughes et al. (2008) found preparation for bias most often in discussions relating to discrimination or unfair treatment, with the aim of instilling coping mechanisms in children. Both children and parents may initiate preparation for bias. Two types of preparation strategies exist: proactive and reactive (Hughes and Chen, 1999; Stevenson, 1999). Proactive strategies are used when parents believe that their children will encounter discrimination and try to equip them with useful skills. Reactive strategies, on the other hand, relate to discussions following incidents that have already occurred. Parental guidance when engaging in these discussions varies. Some parents downplay race-related events and encourage children to ignore them in order to help them cope, while others address the incident directly.

ERS practices vary on both an individual level (depending on the specific characteristics of the parent and the child), and a group level (depending on the characteristics of the ethnic group and other contextual factors). At the group level, studies have shown that preparation for bias may be related to the views of the larger society about a particular ethnic group (Hughes and Chen, 1999; Hughes and Johnson, 2001; Phinney and Chavira, 1995). At the individual level, studies have highlighted the link between ERS and child development. Age is an important predictor of ERS practices. Parents have been found to show similar cultural socialisation levels with their child across their child's lifespan. However, parents are less likely to discuss the complex concept of discrimination and intergroup relations with younger children (Hughes and Chen, 1997, Hughes et al., 2006a, McHale et al., 2006).

Parental characteristics, including socio-economic status, ethnic identity, geographical location and past experiences of racism all influence the type of socialisation strategy used. For example, Hughes et al. (2008) found that parents who had been victims of discrimination, themselves, were more likely to use preparation for bias socialisation with their children.

Literature about the outcomes of using particular ERS parenting strategies is currently not very rich and often relates to adolescents. Findings have been inconsistent, and research relating to child behaviour and psychological adjustment, in particular, is under developed and often conflicting and incomparable because of methodological problems relating to sample characteristics and data analysis techniques (Hughes et al., 2008).

Compared to the US, little research has been conducted in Britain. Existing ERS studies are mostly limited to understanding cultural socialisation practices such as transmission of culture in ethnic groups and processes of acculturation (Robinson, 2009; Barn, 2006; Lau, 2000; Rutter et al., 2005; Berthoud, 2000; Marshall et al., 1998), while less often relating to practices (such as preparation for bias) arising from intergroup contact. Furthermore, studies often tend to ignore the majority ethnic group. In the UK, literature exploring ERS in the White majority ethnic group include that of Holden (2006), who examined the views of 
young people and teachers in two northern UK cities with an emphasis on interfaith dialogue. The research revealed that teachers who strive to incorporate multicultural elements into their curriculum and discuss diversity in the classroom, experience objections from parents, who find that those practices undermine what it means to be British. On the other hand, Reay et al. (2006) identified White middle class families from three areas in England who chose to place their children in ethnically-mixed secondary schools to allow them to experience diversity and build up cultural capital.

\subsection{Why use preparation for bias?}

Hughes et al. (2008) discussed three main goals behind preparation for bias: (1) equipping a child with tools for success, such as education, (2) increasing a child's psychological resources, such as their self confidence and determination, and (3) protecting the emotional state of a child who has just encountered discrimination.

Ethnic inequalities and stressful environments have been associated with unfavourable developmental profiles in children (Shonkoff, 2000; Duncan, 2005). Numerous studies have highlighted the negative association between developmental outcomes (e.g. socioemotional adjustment) and discrimination (Hughes et al. 2009; Brody et al., 2006; Rivas-Drake et al., 2008; Nyborg, 2003; Coker, 2009; Caughy 2004). A recent British study found that mothers' experiences of racism were associated with markers of early child health and development in 5 year olds, including increased risk of obesity. Mothers' perceptions of racism in their residential neighbourhoods were also linked to child socio-emotional difficulties (Kelly et al., 2012).

Given these findings, preparation for bias socialisation can serve as an important parenting mechanism, but just how does this mechanism work? Well there are no definitive answers yet, but a growing body of research in the US has described ethnic-racial socialisation practices as protective buffering factors between racial and ethnic discrimination and development outcomes. For example, cultural socialisation and moderate preparation for bias have been found to act as buffers between racism and self esteem, stress and conduct problems in youth (Neblett et al., 2012; Harris-Britt el al., 2007). They effectively form a means of resilience from negative environmental factors. Recent studies have found associations between ERS (particularly cultural socialisation and preparation for bias) and academic motivations/outcomes (Bennett, 2006; Brown et al. 2009; Smalls, 2009) and ERS and socioemotional adjustment (Constantine and Blackman, 2002; Hughes et al., 2006; Neblett et al al., 2008; 2006; Rivas-Drake, 2011). Other studies have found cultural socialisation and egalitarian messages as predictors of positive self-concept (Bowman and Howard, 1985; Davis and Stevenson, 2006). However, not all socialisation is positive. Negative developmental outcomes have also been reported in relation to specific forms of ERS (Marshall, 1995; Neblett et al., 2006; 2008). For example, preparation for bias messages on their own have been found to contribute to negative self-esteem in youth by causing them 
to feel lack of control over their environment and subsequently to disengage from school and other social activities (Hughes et al., 2009).

To further investigate whether preparation parenting occurs in British samples more research was needed. Keeping this in mind, I now present findings from a novel multi-methods research project of family life in multicultural Britain.

\section{A study of preparation for bias parenting in the UK}

\subsection{Methods}

Thirty-six British-born mothers with children aged 5-7 years (12 British Indian, 12 British Pakistani, 12 White non-immigrant) living in highly diverse urban neighbourhoods were interviewed in depth. These mothers represent a subset of a sample of 90 mothers from a larger study on parenting and child development in non-immigrant White and second generation Indian and Pakistani families. Mothers were recruited mainly through state primary schools in London, located in areas with high concentrations of Indian and Pakistani ethnic populations as well as sizable White populations. In total, children were recruited from 40 schools. London was selected as it hosts the largest population of ethnic minority populations in the country, with groups living in close proximity and engaging in routine interaction. Mothers were interviewed at home with each visit lasting approximately 2-2.5 hours. A trained researcher conducted in depth interviews with mothers, questionnaires, a child test and observational measures. Only data from the qualitative portion of the interview are presented here.

\subsection{The sample}

Strict criteria were administered in the selection of the sample. Data from the most recent census for the London area was used to obtain a demographically matched group of participants. A purposive sampling approach was then employed to achieve a good crossrepresentation of the larger sample for the qualitative analysis. Utilising a purposive sample allowed for a range of viewpoints from mothers to be adequately portrayed and for a balance in socio-economic status and child gender between groups.

Non-immigrant White, Indians and Pakistanis represent the three largest ethnic groups in Britain today. Moreover, the South Asians formed some of the first immigrants to the country arriving from the former imperial empire. They now have well established social networks in the UK and are well into their second and third generations. The Indian community began their mass migration in the 1950s and 60s (Robinson, 1986). The population today is nonhomogenous, constituting of different subgroups including Sikhs and Hindus from Punjab and a large proportion of Gujratis, both Hindu and Muslim. Recent demographic data shows this group tends to be in a more advantageous position in Britain as compared to the Pakistani group. Data also shows approximately half of all Indians in Britain today were born here. 
Two major periods of migration existed for Pakistanis; the 1960s, when mainly male migrants arrived and the 1970s-80s, when their families followed. By 2001, 55\% of the Pakistani population was British-born. The largest ethnic group in the UK is the White nonimmigrant group (Connolly and White, 2006). This group is heterogeneous in terms of social class and national identity, defining themselves as British, English, Scottish, Welsh or some other identity. About $58 \%$ of individuals from the White British group are likely to describe themselves as British (Connolly and White, 2006).

\subsection{Data Analyses}

Part of the data collected from the interviews were analysed qualitatively (presented here). The qualitative sections of the interviews ranged in duration from forty to sixty minutes and were digitally recorded with the parent's consent. None of the parents refused permission. The thematic analysis approach as outlined by Braun and Clarke (2006) was used. Responses were first transcribed verbatim. Transcripts were then read several times to establish familiarity with the mother's responses and allow for preliminary coding. Data was then processed further using computer analysis software (ATLAS-Ti) in order to conduct the detailed thematic analysis. Relevant quotations in the data were first highlighted, and codes were generated from the data. Following this, the codes were revisited and themes were created based on data patterns. These themes were then reviewed and organised into families to help further organise the data. The thematic analysis approach allowed for the identification of emerging and comparative themes under each topic area (see Braun and Clarke, 2006).

\section{Findings}

A range of issues relating to ethnic identification, cultural practices, cultural maintenance and experiences of racism were discussed by mothers, which helped unpack how race and ethnicity influenced their children's and own lives. These are presented below. Any identifying information has been removed or altered to protect the identity of participants and maintain confidentiality. Pseudonyms have been used throughout. These pseudonyms were reflective of the women's ethnic group.

Different forms of ethnic-racial socialisation were identified in parenting practices of the sample, which varied in expression and use across groups and in comparison to past findings in the US. This difference may be due to the young age of the children. Overall ERS was found to be an important part of family life (Iqbal, in press). Mothers from the three groups were found to use preparation for bias parenting strategies. These were reported most in the British Pakistani families and least in the British Indian families, with non-immigrant reporting intermediary use of multicultural preparation parenting. Three main findings relating to preparation parenting were identified: 1) The importance of setting 2) the use of proactive preparation parenting strategies and 3) the use of reactive preparation parenting strategies. 


\subsection{The importance of setting in multicultural parenting}

The complex intertwining of issues relating to ethnicity and race in the daily routines of families living in urban settings became clear during the interviews with mothers. The setting in which intercultural interactions were occurring was found to be particularly important as it facilitated the types of interactions that occurred and seemed to influence how parents negotiated race- and ethnicity- related issues with their children. Mothers discussed how different communities continuously came face to face in the neighbourhoods in which they lived and discussed the implications of this, one of which was discrimination.

Pakistanis reported experiencing the most discrimination compared with the other groups and mothers discussed feeling victimised due to religious beliefs. They blamed the media and political events for creating a highly Islamophobic environment in Britain. Below, a Pakistani mother Jannat narrates an experience she had while with her child on a bus. It is but one example of the types of statements mothers made relating to this issue.

The bus was quite full, I had my child with me, and somebody got up and I sat down. And then I offered it to an old lady next to me. She said she didn't want it. And the lady next to her had a big complaint, 'Oh people like you that have come to this country. You know, you think just cause you've got a child you can just take a seat, and you don't offer. '... But actually I did offer the old lady. But she didn't obviously realise that. And I was brought up in this country... you know, maybe it was because of the clothes that I was wearing.

\section{Jannat, British Pakistani mother}

White and Indian mothers also described Muslims as more likely to face discrimination in contemporary Britain. Indian mothers on the other hand, reported experiencing the least discrimination

An important finding was the discussion of experiences of discrimination by White families. Non-immigrant White mothers spoke of feeling stereotyped in increasingly ethnically-diverse neighbourhoods. They gave examples of not being treated equally in the public space, of worrying that their children were being alienated at school and of feeling that other ethnic groups were quick to label them as being racist when they voiced their feelings.

One aspect of this was 'informal segregation', an idea discussed by a number of White mothers. This refers to the existence of neighbourhoods with high proportions of ethnic minorities and low proportions of the majority group. One reason for these neighbourhoods is the outward migration from the neighbourhood of many non-immigrant White families, with minority groups choosing to stay. The White families that do remain in these minoritydominated neighbourhoods experience a shift in the balance of demographics, causing some to worry. A number of mothers were very forthcoming about expressing concerns, whilst others expressed anxieties more indirectly. Mothers stated that they worried about their child not having anyone from their own ethnic group to 'identify' with at school, currently and in the future. 
As I say, there is nobody in his class that he could really identify with on that level because a lot of the children there have been brought up in a different - not a different way, but probably some of them have been brought up differently but obviously it isn't the same. As much as they all play together and they get on, um, I would like there to be more White children.

Stephanie, non-immigrant White mother

A number of White mothers discussed the importance of their child having a friend from the same ethnic group. They also felt that children and families from other minority groups excluded their children from parties and play dates. This exclusion may have been intentional or unintentional. In her narrative, Hannah begins with a clarification that she is not being racist; this shows that she feels insecure about expressing her worries about her child being possibly marginalised by other children.

Yeah. I mean, I'm not racist at all, but I do feel . . I mean my eldest son . . . he's . . . he's one of two White people in his class. So to me, that's unfair. Because it should be ... if it's going to be multi-cultural, let it be multi-cultural. Not one-sided . . do you know what I mean? . . . But a lot of the time, you find they're actually quite racist. Um, [child] bless him, he doesn't get invites to their houses,. . . so it is my close friends that we deal with.

Hannah, non-immigrant White mother

Not all mothers viewed this imbalance as completely negative, with some non-immigrant White mothers actively choosing to live in very multicultural neighbourhoods and embracing diversity.

Understanding parents' experiences of living in diversity is important as it sheds light on one of the reasons why they may opt for preparation for bias parenting strategies. More about the use of preparation parenting and its use by parents is discussed below.

\subsection{Preparation for Bias}

Preparation for bias was found in all groups, illustrating that it is not only a minority parenting strategy, but a majority parenting strategy also. This reflected the highly multicultural nature of the neighbourhoods in which the families lived. Overall it was reported more in Pakistani and White families compared to Indian ones. Preparation for bias was complex, often existing alongside other parenting strategies, particularly egalitarianism.. Another aspect of preparation for bias was the form in which it took, with mothers acting either proactively or reactively. In proactive approaches, mothers tried to ensure that their children had all of the tools needed to cope with prejudice as well as the skills needed to avoid prejudice. Reactive parenting was less anticipatory in nature and was not part of a parenting agenda. It was often linked to a particular incident or series of incidents around race. Mothers used different approaches to guide and explain the event to their children, such 
as encouraging them to ignore the event, downplaying the race element of the event and equipping their children with emotional coping strategies. The results are divided accordingly.

\subsection{Proactive Parenting}

Only one mother from the British Indian group discussed using a proactive stance when parenting. She spoke to her child about being independent and fighting for his rights and gaining a good education, thus equipping him with tools for success. This was in anticipation of future experiences of discrimination. Overall, in the British Pakistani group, a large number of mothers discussed the use of preparation for bias parenting, and there was a fairly equal mixture of mothers using the proactive versus reactive approach. British Pakistani mothers seemed to anticipate that their children would encounter more discrimination. Similar to mothers from the two other groups, some mothers used the discussion of 'people being horrible to one another' as a way of talking about racism without talking about the 'full-blown subject'. For some families, it was a discussion that came up often, and mothers were very straightforward in how they discussed the subject, with the child understanding the concept of discrimination. A particular group of Pakistani mothers discussed anticipating that their child would face prejudice from a young age. These were mothers and children who wore niqab or hijabs. The headscarf, they felt was a strong symbol which caused non Muslims to see them as being different and thus made them more vulnerable to intolerance from others. These mothers wanted to ensure their children understood why they wore the headscarf and instil an inner strength in them. It could also be seen as an example of preparation for bias and religio-cultural socialisation occurring alongside, thus highlighting the complex intertwined nature of ERS.

Inshallah. Before like after summer sometime she'll start. But it's something, obviously I keep installing into her, um . . . Like I don't say: 'Oh you have to!' It's always like okay, you know, this is what ... this is what, you know what Allah wants and you know. . . make them love it, and make sure that ... make them show that it's not a bad thing. But you know, Alhamdollillah, but a lot of people do cover in school who are even younger than her, so I don't think it's asking a lot.

Aisha, British Pakistani mother

The non-immigrant White group also used proactive preparation for bias strategies. Mothers explained how they discussed the changing nature of British society with their children in order to help them understand diversity, and negative elements that could sometimes arise from it. Some White Mothers anticipated that their children would either be discriminated against because they were occasionally in a minority (discussed earlier as informal segregation), or falsely accused of being racist towards non-White individuals . In the first case, one mother, Emma, discussed speaking to her child about immigration and how being born in Britain meant 'non-White people could be British'. Another mother, Hannah, felt angry that White people were so easily accused of being racist. She stated that her far- 
removed ancestors may have discriminated against minorities, but not her. She explained this to her daughter.

I might say something and then someone might say, 'Oh, you're racist', and I'll be like . . or they'll have a chip on their shoulder, and be like saying about the slaves back in the day. And I'm like, but that wasn't me. Wasn't even my Nan. Wasn't even my great Nan. Probably went way back, you know, and like it's ... it's just like we need to get over that now, and just deal with what we're at, and that is what I tell her [the child]

\section{Hannah, non-immigrant White mother}

By explaining this history to her, Hannah is increasing the psychological resources available to her daughter should she ever experience bias.

A type of proactive preparation for bias strategy specific to the White group, related to mother's perception of informal segregation. Mothers reported concern with the imbalance in the classroom and neighbourhoods in which they lived, and particularly that their child might stand out as being different from the others. Two White mothers reported changing their child's school, as they worried about them being marginalised. One of these was Anna who spoke about the experience she had with her child and their new school after moving to a new, extremely multicultural, area.

When she started going to school there we felt there were no other people like us. It's really hard to explain. There were no other White middle class . . people with their kids there. There's a very, very big community of Pakistan, Muslim kids, and Somali Muslim kids, and so a lot of the people [the child] made friends with were Muslim girls, and they weren't allowed to mix with her out of school. I don't know. And it was quite a big issue, and just us not feeling that there was anyone else like us, and so we changed... [another] school.

Anna, non-immigrant White mother

Whether this movement could be interpreted as preparation for bias strategy or promotion of mistrust socialisation by these mothers is important. In the narrative Anna described her child feeling excluded and not being invited to other children's homes. This resulted in her having to explain difference between groups to her child and preparing her for more of this in the future. In order to avoid this 'constant explanation' she described proactively changing her child's setting to a more 'healthy' mix of ethnicities in the classroom with more White children in the anticipation that her child would experience less marginalisation in this setting. Yet it could also suggest her being uncomfortable with too much diversity and feeling like a minority group member. 
Overall, the young age of their child was a universal factor which influenced the degree to which parents from each group proactively spoke about bias with their children. Despite some groups encountering more discrimination than others, age very much played a part in decision making.

\subsection{Reactive Parenting}

In the British Indian group, there were fewer examples of this type of parenting. Mothers discussed incidents of their child being exposed to media images around race and of how they encouraged their child to ignore what they had witnessed. A number of mothers in this group felt their child was too young to cope with understanding race and discrimination and they thus chose not to broach the subject, even when the child had witnessed or been part of a race-related incident. Some mothers partially explained to their children that only a minority of people were racist, and that they should just ignore them.

Umm, he [the child] was studying at school and there is a Pakistani child there and they said to them, 'Sikhs are no good, we hate Sikhs', and I told him, 'Look, son, not everyone is the same, you know.'

\section{Rani, British Indian mother}

The more reactive types of preparation strategies often followed Islamophobic incidents. Mothers frequently downplayed incidents or used other means to help the child emotionally come to terms with the incident. One mother, Feroz, talked about a time when she wore a niqab and a group of teenagers insulted her in front of her children, which caused them distress.

I used to wear a niqab. I did it because I thought that that would make me closer to Allah. Then I got lots of uh, racist [comments]. . . actually to my face. I used to get people walking by me, effing at me and my children. I could see it was affecting my son. There would be a certain group of teenagers. We used to walk past the high school. And they would say to, you know, like uh, comments. Just rude. You know, just eff . . or um, just derogatory comments ... and then he was getting angry. He was only eight or nine at the time

\section{Feroz, British Pakistani mother}

Feroz worried that, as a result of this racism, her children would be very negative in their views towards White people. She tried to explain to her children that the troublemakers were only a minority.

He would say ... "I'm not going to go to that school". And he was determined, too . . and I found that really sad. I just thought, that he shouldn't discriminate against a whole bunch of people because there's [sic] a few idiots and you know, I explained this to him. I used to feel we were vulnerable. 
In this way Feroz used preparation strategies both to protect the emotional state of her child by explaining the bullies were only in a minority, but also attempted to equip him with tools for success by explaining the importance of tolerance in functioning productively in British society. Another British Pakistani mother, Shazia, discussed downplaying an incident to her child when a woman was racist at a local swimming pool. She told the child that the woman was 'ignorant and rude' and 'didn't understand things'. This served as a means of protecting her child at a young age and creating an explanation that would not upset her daughter.

In the non-immigrant White group, most discussion around racial intolerance was in direct response to a race-related incident that had occurred in the mother or child's life and was, therefore, a reactive strategy. The event may have come up in the media, through an experience at school or during an everyday routine. For example, one mother, Tracy, encouraged her child to ignore news reports and comments made by others when they related to racism, and tried to answer her child's questions in a neutral way.

Probably if it's just come up on the news... if he hears it. Obviously there is quite a lot of it, so he will ask questions about and I'll try and explain what's going on, and, I just kind of say to him that you need to ignore it babe, and . . just kind of get on with it. Don't bite back to it if it happens, because it just seems to be that that's what they want.

Tracy, non-immigrant White mother

Mothers who ignored racist incidents or downplayed them tended to do so as part of a protective approach. Stephanie, a non-immigrant White mother, used this approach. She narrated an incident in which her child wanted to eat halal food at his school canteen. The child was copying his Muslim friend, but was told roughly 'No!' by the dinner lady because he was 'not Muslim' and without any further explanation. This event upset her child, who came home and asked, 'Mum, am I only allowed to eat Christian food?'

Fair enough if they only order so much in that they can't give it to everybody but there are ways of kind of explaining that to children. I thought you are not really helping by dealing with it like that, by saying, 'Well you can have that but you can't have it because you are clearly not a Muslim child you are a white English child and you are not allowed to have it! 
Stephanie was forced to discuss with her child why this had happened. She explained that Muslims had separate diets and, in this way, helped her son cope with the emotional aspects of the event. This explanation was very much reactive in nature and specifically incident related.

So I had to kind of explain it to him, but even myself I was thinking - it's a bit bad. I think sometimes schools don't deal with things in the correct way, even though they do try. Suppose things like that you wouldn't call a racist incident, but it shows the differences - it's making him aware of the differences between everyone when really there was no need for it or it could have been dealt with in a more positive way.

Stephanie, non-immigrant White mother

She spoke about being appalled by the behaviour of the school dinner lady and made a complaint.

I thought really - you know schools go on about bullying and racism and all the rest of it... like they do their projects and everything like that, but things like that are a simple thing to a six-year-old and he was like, completely confused by it and didn't know what they were talking about and why he couldn't have it. I spent a long time explaining.

\section{Stephanie, non-immigrant White mother}

This example shows the complex ways in which race and religion can influence daily routines and choice in a child's life. The way in which the child has been socialised to interpret such an incident is important. Another example of an incident described by a nonimmigrant White mother that took place, again, at school, involved the child's ten-year-old brother being accused of being racist towards a Black child by another mother at his school. This had resulted in the brother being put on probation for two weeks.

When one of my other sons was in primary school, um, he didn't like this boy in his class. And his mother said 'it's because he's racist, he doesn't want to play with my son because he's Black". And, um, so the school kind of pointed out that all of [the brother]'s other friends were Black, and so they didn't understand how this could be construed as racism. Anyway, so then they ... observed [the brother] for two weeks. Watched him play. Watched him to do this, and had to write everything down... That was their policy.

Hailey, non-immigrant White mother 
This non-immigrant White mother (Hailey) was forced to answer some tough questions to her older son, about why he was being observed. The school later agreed that the child had been wrongfully accused, yet they still observed him to appease the other mother. Hailey discussed her son unfairly being accused as being racist and tried to explain difference to her older son who didn't understand. These events impacted Hailey's parenting of her younger son, and she discussed her choice to remain silent about racism with him because of how much the incident had affected his brother. She felt that this was the most effective means of protecting her child.

The part of it that I found really difficult, was then I had to sit down and talk to [the brother] about racism. And discuss what it meant, and. . he didn't really get it. Do you know what I mean? And he was about the same age as [the child] is now. And he didn't get it, and it just kind of confused him. So, for that reason, I've never really. I've never brought . the topic up, just from previous experience.

\section{Hailey, non-immigrant White mother}

Both Stephanie's and Hailey's examples show the role schools play in ethnic-racial socialisation. Schools are arenas in which race related events can unfold but they also play a role in managing these issues in children's day to day lives. As described in the above narratives, parents do not always agree in the way schools handle these issues.

Some mothers chose to use an egalitarian explanation to help their children understand that, even though they had been victimised, every person is equal and the people who had been racist were a small minority. This served as a means of coping with emotional consequences of discrimination, as well as increasing a child's psychological resources such as self-worth. It was also a way in which types of ethnic-racial socialisation parenting were also found to occur simultaneously i.e. preparation for bias alongside egalitarianism.. An example of this was noted in a discussion with a non-immigrant White mother, Tracy, when she spoke of the racism experienced by her child and how she used egalitarianism-based discussions to make him stronger and prepare him for any further bias he may encounter.

We've got a girl that lives on the top floor. Um she had some friends over and obviously they're not White. And um, he was playing downstairs with some friends and they were calling them like 'White rats'. And you know - the names. I just sit there and my attitude is ... you're no different, you are a different colour but you're no different to us. You know so I do explain to him, you know, I won't have it. I won't have racism at all. So I don't agree with it. Because I do believe we're just all 
the same. It doesn't matter where we're from or who we are. We're still human. We still have feelings, you know.

Tracy, non-immigrant White mother

\section{Discussion}

The present study is one of the few available studies to investigate preparation for bias socialisation in young children. It also places ethnic-racial socialisation in a British context.

Regardless of ethnicity or place of birth, it was found that Indian, Pakistani and White families were encountering issues around race, ethnicity and culture on a frequent if not daily basis, and thus using ethnic-racial socialisation parenting practices extensively. Preparation for bias represented one form of this. It was found to be multifaceted and occurred in different contexts. It also varied in frequency of use in each family type. The highest incidence was reported in Pakistani families, while Indian families used this type of socialisation less often. White families lay between the two groups in terms of how much preparation parenting was used. Setting was also found to be an important factor in influencing the utilisation of preparation parenting by familes.

These findings have important implications. They shed light on the socio-cultural adaptation of families in the study, highlighting that some families opted for preparatory strategies often alongside integration strategies (such as egalitarianism). What was particularly interesting was the use of preparation for bias by White majority families indicating their anticipation of experiencing as well as actual experience of bias and/or marginalisation in intercultural relations.

The paper set out to argue that increased diversity in the UK has caused host society members as well as some minority groups to adapt parenting strategies according to their surrounds and resulted in these groups being forced to make challenging parenting decisions around race and ethnicity. The findings clearly lay out some of these challenging decisions parents have had to make. They also point to idea of surround/environment as a playing a key role in preparation parenting.

Stressful environments and ethnic inequalities have been found to be associated with unfavourable developmental profiles in children (Shonkoff, 2000; Kelly et al., 2006; Duncan, 
2005). A recent study in the UK with 2136 mothers and their 5 year old children found data that supported that mothers' experiences of racism were linked to markers of early child health and development in a UK context also. Mothers who had experienced interpersonal racism were found to be more likely to have children with a higher risk of obesity. Further, mothers' perception of racism in residential areas was associated with socioemotional difficulties in children (Kelly et al., 2012). This study used data from the UK Millennium Cohort Study and mothers and children were from the main ethnic groups in the UK including White, Pakistani and Indian families.

In the present study, the idea of informal segregation, as brought up by White mothers in the study is an example of the importance of environment. The perception of no longer being in the majority and thus more susceptible to bias, caused more White mothers to use proactive preparation with their children. Moreover experiences of discrimination by this group and also to a greater extent by the Pakistani group in an Islamophobic Britain were shown to increase reactive preparation parenting. It is important to also point out here, that the families in the study lived in inner urban settings (Bolognani et al., 2011). Whether the same parenting strategies are used by parents in towns and more rural areas with different ethnic groups is an important question that needs further exploration.

Schools as social settings for race/ethnicity related events also serve to strengthen the argument about the role of settings. Some of the examples of incidents described by mothers highlight the important roles primary schools can play in conceptualising race and ethnicity in children's lives. The question of how schools do this is particularly important. Despite the overall curricula following a 'softly-softly' egalitarian based agenda (often not addressing issues such as racism directly), as the examples show, the gap in theory and actual practical application does not seem to always overlap, potentially causing frustration in some families. Discontent in such areas can sow the seeds for future inter-ethnic tension between groups and it seems more of an attempt made across all adults in the school, including support staff is needed in order to have a unified approach to ethnicity and race related issues. Furthermore, greater understanding is needed about the positive and negative effects of utilising particular types of socialisation at school.

Overall, the types of socialisation used in families suggests that parents were often instilling protective and positive messages in their children around race and ethnicity (i.e. through 
cultural socialisation combined with moderate preparation for bias and egalitarianism) that correspond to positive socialisation as described in past literature. Thus far, few studies have explored the buffering protective effects of ERS on developmental outcomes (see Neblett et al, 2010). Furthermore, these have often been explored in youth and not in young children. They have suggested ethnic identity and self esteem to be mediating mechanisms in the protective process. They also suggest that ERS may help with coping responses to discrimination, positive self perception and resistance to negative treatment. Preparation for bias is important in this. As discussed earlier this socialisation type has 3 main functions; equipping children with tools for success (such as education), increasing psychological resources in children such as self confidence and determination and protecting a child's emotional state following a race related incident. Each of these was found in the families in the study in their discussion of preparation parenting.

A recent integrative conceptual model which offers an explanation of factors which may interact to shape positive development in youth has been developed by Neblett and colleagues (2012). This includes racial and ethnic identity, ERS and cultural orientation as important components. Ethnic-Racial Socialisation functions in the model as a means by which youth prepare to perceive the world in a certain way. Self-concepts, cognitive appraisal processes (how youth take part, understand and make sense of the world) and coping are all important protective mechanisms in this model. Importantly, it stresses that racial/ethnic identity development, the instilling of family values and cultural socialisation begin early in life, and evolve though time. Thus, it is important to explore these processes in children as well as through key developmental periods. There is a strong need for future research in this area.

The paper raises some important questions about parenting in multicultural areas and how families adapt to their surrounds. It also highlights the ever present and subtle nature of race and ethnicity and its effect on daily family life. The impinging presence of discrimination is but one aspect of this. How families choose to handle this marginalisation is important. The preparation strategy is one option parents have, which represents a more positive approach rather than promotion of mistrust. Further exploration of its use across ethnicities and developmental periods is needed. Moreover, policy makers strongly need to acknowledge its use in all groups including the White majority group, and particularly their changing feelings around race and ethnicity in multicultural urban centres. 


\section{Acknowledgements}

I would like to thank Professor Susan Golombok for supervising the present research work and Professor Carol Vincent and Dr Gabriela Roman for help with editing this paper. Thank you also to all of the families that took part in this research.

\section{References}

Barn, R. with Ladino, C. \& Rogers, B. (2006). Parenting in Multi-Racial Britain. London, United Kingdom: NCB

Bennett, M. D. J. (2006). Culture and context: A study of neighbourhood effects on racial socialization and ethnic identity content in a sample of African American adolescents. Journal of Black Psychology, 32, 479-500.

Berthoud, R. (2000). Family formation in multicultural Britain: three patterns of diversity. Working Papers of the Institute for Social \& Economic Research, Paper No. 34.

Bolognani, M., Hyder, E., Iqbal, H., Sabri, Z. (2011). '101 damnations': British Pakistanis, British cinema and sociological mimicry. South Asian Popular Culture. 9 (2).

Bowman, P. J., \& Howard, C. (1985). Race-related socialization, motivation, and academic achievement: A study of Black youths in three-generation families. Journal of the American Academy of Child Psychiatry, 24, 134-141.

Boykin, A. W., \& Toms, F. D. (1985). Black child socialization: A conceptual framework. In H. P. McAdoo \& J. L. McAdoo (Eds.), Black children: Social, educational, \& parental environments (pp. 33-51). Newbury Park, CA: Sage.

Braun V and Clarke V (2006). Using thematic analysis in psychology. Qualitative Research in Psychology, 3(2), 77-101.

Brody, G. H., Chen, Y., Murry, V. M., Ge, X., Simons, R. L., Gibbons, F. X., et al. (2006). Perceived discrimination and the adjustment of African American youths: A five-year longitudinal analysis with contextual moderation effects. Child Development, 77, 11701189.

Brown, T. L., Linver, M. R., Evans, M., \& DeGennaro, D. (2009). African-American parents' racial and ethnic socialization and adolescent academic grades: Teasing out the role of gender. Journal of Youth and Adolescence, 38, 214-227.

Caughy, M.O., O’Campo, P.J., \& Muntaner, C. (2004). Experiences of racism among African American parents and the mental health of their preschool-aged children. American Journal of Public Health., 94, 12118-24. 
Coard, S. I., \& Sellers, R.M. (2005). African American familes as a context for racial socialization. In V.C. McLoyd, N.E.Hill \& K.A. Dodge (Eds.), African American family life: Ecological and Cultural diversity, Duke series in child development and public policy (pp. 264-284). New York: Guilford

Coker TR, Elliott MN, Kanouse DE, Grunbaum JA, Schwebel DC, Gilliland MJ, Tortolero SR, Peskin MF, Schuster MA. (2009). Perceived racial/ethnic discrimination among fifthgrade students and its association with mental health. American Journal of Public Health. 99, 878-84.

Constantine, M. G., \& Blackmon, S. M. (2002). Black adolescents' racial socialization experiences: Their relations to home, school, and peer self-esteem. Journal of Black Studies, 32, 322-335.

Connolly, H. \& White, A. (2006). The different experiences of the United Kingdom's ethnic $\&$ religious populations. Social Trends, 36, 1-8.

Davis, G. Y., \& Stevenson, H. C. (2006). Racial socialization experiences and symptoms of depression among Black youth. Journal of Child and Family Studies, 15, 303-317.

Duncan, G.J. \& Magnuson, K.A. (2005). Can family socioeconomic resources account for racial and ethnic test score gaps? Furture Child, 15,35-54.

Hamm, J. V. (2001). Barriers \& bridges to positive cross-ethnic relations: African American \& White parent socialization beliefs \& practices. Youth \& Society, 33, 62-98.

Harris-Britt, A., Valrie, C. R., Kurtz-Costes, B., \& Rowley, S. J. (2007). Perceived racial discrimination and self-esteem in African American youth: Racial socialization as a protective factor. Journal of Research on Adolescence, 17, 669-682.

Holden, A. (2006). Evaluating the contribution of interfaith dialogue to community cohesion, available at http://www.lancs.ac.uk/fss/religstudies/research/projects.

Hughes, D., Bachman, M. Ruble, D., \& Fuligni, A. (2006a). Tuned in or tuned out: Children's interpretations of parents' racial socialization messages. In L. Balter \& C. Tamis-Lemonda (Eds.), Child psychology: A handbook of contemporary issues (2nd ed.) (pp. 591-610). Philadelphia: Psychology Press.

Hughes, D., \& Chen, L. (1999). The nature of parents' race-related communications to children: A developmental perspective. In L. Balter \& C. S. Tamis-Lemonda (Eds.), Child psychology: A handbook of contemporary issues (pp. 467-490). Philadelphia: Psychology Press.

Hughes, D., \& Chen, L. (1997). When \& what parents tell children about race: An examination of race-related socialisation among African American families. Applied Developmental Science, 1 (4), 2000-214.

Hughes, D \& Johnson, D.J. (2001). Correlates in children's experiences of parents' racial socialisation behaviours. Journal of Marriage \& The Family, 63(4), 981-995. 
Hughes, D. Rivas, D. Foust, M. Hagelskamp, C, Gersick, S \& N. Way. (2008). How to Catch a Moonbeam: A mixed methods Approach to understanding Ethnic Socialisation Processes in Ethnically diverse Families. In (Ed). Quintana, S \& C McKown. Handbook of Race, Racism \& the Developing Child. New Jersey, John Wiley \& Sons Inc.

Hughes, D., Rodriguez, J., Smith, E.P., Johnson, D.J., Stevenson, H.C., \& Spicer, P. (2006). Parents' racial/ethnic socialization practices: A review of research \& agenda for future study. Developmental Psychology, 42(5), 747 - 770.

Hughes, D., Witherspoon, D., Rivas-Drake, D., \& West-Bey, N. (2009). Received ethnicracial socialization messages and youth's academic and behavioural outcomes: Examining the mediating role of ethnic identity and self-esteem. Cultural Diversity and Ethnic Minority Psychology, 15, 112-124.

Iqbal, H., (2013). Ethnic-Racial Socialisation in the UK: The use of Egalitarianism Parenting in explaining meanings of race and ethnicity in non-immigrant White and British South Asian Families. In, Dimitrova, Bender \& Van de Vijver (Eds). Global Perspectives on Well Being in Immigrant Families, Springer.

Kelly, Y., Becares, L \& Nazroo. J. (2012). Associations between maternal experiences of racism and early child health and development: findings from the UK Millennium Cohort Study. Journal of Epidemiol Community Health. 1-7.

Kelly, Y.J., Sacker, A. Schoon I, \& Nazroo, J. (2006). Ethnic differences in achievement of developmental milestones by 9 months of age: the Millennium cohort Study.

Developmental Medicine and Child Neurology, 48. 823-30.

Knight, G. P., Bernal, M. E., Cota, M. K., Garza, C. A., \& Ocampo, K. A. (1993). Family socialization \& Mexican American identity \& behavior. In M. E. Bernal \& G. P. Knight (Eds.), Ethnic identity: Formation \& transmission among Hispanics \& other minorities (pp. 105-129). Albany: State University of New York Press.

Knight, G. P., Bernal, M. E., Garza, C. A., Cota, M. K., \& Ocampo, K. A. (1993). Family socialization \& the ethnic identity of Mexican- American children. Journal of CrossCultural Psychology, 24, 99-114.

Lau, A. (Ed) (2000). South Asian children \& adolescents in Britain. London: Whurr.

Marshall, S. (1995). Ethnic socialization of African American children: Implications for parenting, identity development, and academic achievement. Journal of Youth and Adolescence, 24, 377-396.

Marshall, H., Woollett, A. \& Dosanjh, N. (1998). Researching marginalized standpoints: some tensions around plural standpoints \& diverse "experiences", in K. Henwood, C. Griffin \& A. Phoenix (Eds.) Standpoints \& Differences: Essays in the Practice of Feminist Psychology. London: Sage. 
McHale, S.M., Crouter, A.C., Kim, J-Y., Burton, L.M., Davis, K.D., Dotterer, A. M., et al. (2006). Mothers' \& fathers' racial; socialisation in African American families: Implications for youth. Child Development, 77(5), 1387-1402.

Neblett, E.W., Jr., Hammond, W.P., Seaton, E.K., \& Townsend, T.G. (2010). Underlying mechanisms in the relationship between Africentric worldview and depressive symptoms. Journal of Counseling Psychology, 57(1), 105-113.

Neblett, E.W., Jr., Philip, C.L., Cogburn, C.D., \& Sellers, R.M. (2006). African American adolescents' discrimination experiences and academic achievement: Racial socialization as a cultural compensatory and protective factor. Journal of Black Psychology, 32(2), 199218.

Neblett, E.W., Jr., Rivas-Drake, D., \& Umaña-Taylor, A.J. (2012). The promise of racial and ethnic protective factors in promoting ethnic minority youth development. Child Development Perspectives, 6(3), 295-303.

Neblett, E.W., Jr., White, R.W., Ford, K.R., Philip, C.L., Nguyên, H.X., \& Sellers, R.M. (2008).Patterns of racial socialization and psychological adjustment: Can parental communications about race reduce the impact of racial discrimination? Journal of Research on Adolescence,18(3),477-515.

Nyborg, V.M. \& Curry, J.F. (2003) The impact of perceived racism: psychological symptoms among African American boys. Journal of Clincal and Child Adolescent Psychology, 32, 258-66.

Ou, Y., \& McAdoo, H. P. (1993). Socialization of Chinese American children. In H. P. McAdoo (Ed.), Family ethnicity: Strength in diversity (pp. 245-270). Thousand Oaks, CA: Sage.

Peters, M. F. (1985). Racial socialization of young Black children. In H. P. McAdoo \& J. L. McAdoo (Eds.), Black children: Social, educational, \& parental environments (pp. 159173). Beverly Hills, CA: Sage.

Phinney, J..S., \& Chavira, V. (1995). Parental ethnic socialization \& adolescent coping with problems related to ethnicity. Journal of Research on Adolescence, 5(1), 31-54.

Quintana, S. M., \& Vera, E. M. (1999). Mexican American children's ethnic identity, understanding of ethnic prejudice, \& parental ethnic socialization. Hispanic Journal of Behavioral Sciences, 21, 387-404.

Reay, D., Hollingworth, S., Williams, K., Crozier, G., Jamieson, F., James, D. \& Beedell, P. (2006) 'Report on identities, educational choice \& the white urban middle classes', unpublished paper prepared for the Ethnicities subgroup of the ESRC Identities \&

Social Action Research Programme 
Rivas-Drake, D. (2011). Ethnic-racial socialization and adjustment among Latino college students: The mediating roles of ethnic centrality, public regard, and perceived barriers to opportunity. Journal of Youth and Adolescence, 40, 609-619.

Rivas-Drake, D., Hughes, D., \& Way, N. (2008). A closer look at peer discrimination, ethnic identity, and psychological wellbeing among urban Chinese American sixth graders. Journal of Youth and Adolescence, 37, 12-21.

Robinson, L. (2009), Cultural Identity \& Acculturation Preferences Among South Asian Adolescents in Britain: An Exploratory Study. Children \& Society, 23: 442-454.

Robinson, V. (1986) Transients, Settlers \& Refugees; Asians in Britain, Clarendon, Oxford

Rutter, M. \& Tienda, M. (2005). Ethnicity \& Causal Mechanisms. Cambridge: Cambridge University Press.

Shonkoff, J.P., \& Phillips, D.A. (2000). From Neurons to Neighbourhoods: The Science of Early Childhood Development. Washington, DC: National Academies Press.

Smalls, C. (2009). African American adolescent engagement in the classroom and beyond: The roles of mother's racial socialization and democratic-involved parenting. Journal of Youth and Adolescence, 38, 204-213.

Spencer, M. B., \& Markstrom-Adams, C. (1990). Identity processes among racial \& ethnic minority children in America. Child Development, 61, 290-310.

Spencer, M. B., \& Markstrom-Adams, C. (1990). Identity processes among racial \& ethnic minority children in America. Child Development, 61, 290-310.

Tatum, B. D. (1987). Assimilation blues: Black families in a White community. Westport, CT: Greenwood Press.

Thornton, M. C., Chatters, L. M., Taylor, R. J., \& Allen, W. R. (1990). Sociodemographic \& environmental correlates of racial socialization by Black parents. Child Development, 61, 401-409.

Umana-Taylor, A. J., \& Fine, M. A. (2004). Examining ethnic identity among Mexicanorigin adolescents living in the United States. Hispanic Journal of Behavioral Sciences, 26, 36-59.

Vertovec, Steven. (2007). Superdiversity and its Implications. Ethnic and Racial Studies. 30(6). 1024-54. 